\title{
Lusioersily
}

\section{Maternal vitamin D and markers of glycaemia during pregnancy in the Belfast centre of the Hyperglycaemia and Adverse Pregnancy Outcome study}

Casey, C., McGinty, A., Holmes, VA., Hill, A., Patterson, CC., Young, IS., \& McCance, DR. (2018). Maternal vitamin $\mathrm{D}$ and markers of glycaemia during pregnancy in the Belfast centre of the Hyperglycaemia and Adverse Pregnancy Outcome study. Diabetic medicine, 35(7), 972-979. https://doi.org/10.1111/dme.13632

Link to publication record in Ulster University Research Portal

Published in:

Diabetic medicine

Publication Status:

Published (in print/issue): 19/06/2018

DOI:

10.1111/dme.13632

Document Version

Author Accepted version

\section{General rights}

Copyright for the publications made accessible via Ulster University's Research Portal is retained by the author(s) and / or other copyright owners and it is a condition of accessing these publications that users recognise and abide by the legal requirements associated with these rights.

\section{Take down policy}

The Research Portal is Ulster University's institutional repository that provides access to Ulster's research outputs. Every effort has been made to ensure that content in the Research Portal does not infringe any person's rights, or applicable UK laws. If you discover content in the Research Portal that you believe breaches copyright or violates any law, please contact pure-support@ulster.ac.uk. 
DR CLAIRE CASEY (Orcid ID : 0000-0001-9188-6801)

DR VALERIE HOLMES (Orcid ID : 0000-0001-6229-5703)

Article type : Research Article

Title: Diabetic Medicine

Created by: Maria Davie

Email proofs to: david.mccance@belfasttrust.hscni.net

Article no.: DME-2017-00742

Article type: Research Article

Short title/Authors running head: Vitamin D and glycaemia during pregnancy $\bullet$ C. Casey et al.

\section{Research: Pregnancy}

\section{Maternal vitamin D and markers of glycaemia during} pregnancy in the Belfast centre of the Hyperglycaemia and

\section{Adverse Pregnancy Outcome study}

C. Casey $^{1}$, A. McGinty ${ }^{1}$, V. A. Holmes ${ }^{1}$, A. J. Hill ${ }^{2}$, C. C. Patterson ${ }^{1}$, I. S. Young $^{1}$ and D. R. McCance ${ }^{1,3}$

${ }^{1}$ Centre for Public Health, Queen's University Belfast, Belfast, ${ }^{2}$ NICHE, School of Biomedical Sciences, Ulster University, Coleraine and ${ }^{3}$ Regional Centre for Endocrinology and Diabetes, Royal Victoria Hospital, Belfast, UK

This article has been accepted for publication and undergone full peer review but has not been through the copyediting, typesetting, pagination and proofreading process, which may lead to differences between this version and the Version of Record. Please cite this article as doi: 10.1111/dme.13632

This article is protected by copyright. All rights reserved. 
Correspondence to: David R. McCance. E-mail: david.mccance@ belfasttrust.hscni.net

\section{What's new?}

- This was a large-scale observational study reporting serum vitamin D concentrations in a pregnant population in Northern Ireland.

- The study shows a high level of vitamin D deficiency in a white European cohort at $55^{\circ} \mathrm{N}$.

- The study suggests that vitamin D and glucose metabolism in pregnancy are not linked.

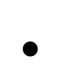

\section{Abstract}

Aims To measure total 25-hydroxyvitamin D levels in women in mid-pregnancy who participated in the Belfast centre of the Hyperglycaemia and Adverse Pregnancy Outcome (HAPO) observational study, and to investigate the associations between levels of 25hydroxyvitamin D and markers of gestational diabetes mellitus and lipid biomarkers.

Methods A total of 1585 pregnant women had serum samples available for measurement. Participants were recruited from the Royal Jubilee Maternity Hospital, Belfast, Northern Ireland, at 24-32 weeks' gestation, as part of the HAPO study. 25-hydroxyvitamin D concentrations were measured using liquid chromatography tandem mass spectrometry. Glucose, C-peptide and lipid levels were previously analysed in a central laboratory. Statistical analysis was performed. 
Results The median (interquartile range) 25-hydroxyvitamin D concentration during pregnancy was $38.6(24.1-60.7) \mathrm{nmol} / \mathrm{l}$, with $65.8 \%$ of women being vitamin D-deficient $(\leq 50 \mathrm{nmol} / \mathrm{l})$. In regression analysis, the association between maternal 25 -hydroxyvitamin $\mathrm{D}$ and fasting plasma glucose levels approached significance [regression coefficient -0.017 (95\% CI -0.034 to 0.001$) ; P=0.06]$, and a significant positive association was observed between maternal 25-hydroxyvitamin D and $\beta$-cell function [1.013 (95\% CI 1.001 to 1.024); $P=0.031]$. Maternal 25-hydroxyvitamin D level was positively associated with HDL [0.047 (95\% CI 0.021 to 0.073$) P \leq 0.001]$ and total cholesterol [0.085 (95\% CI 0.002 to 0.167 ); $P=0.044]$ in regression analysis.

Conclusions These results indicate a high prevalence of vitamin D deficiency during pregnancy, which requires identification and treatment; however, only weak associations were observed between 25-hydroxyvitamin D level and markers of glucose and insulin metabolism. This would suggest that these are of doubtful clinical significance.

\section{Introduction}

Vitamin D sufficiency during pregnancy is of the utmost importance because vitamin D diffuses across the placenta and is transferred to the neonate; as a result, maternal deficiency will translate into neonatal deficiency [1]. A systematic review of the global prevalence of deficiency (defined as $<50 \mathrm{nmol} / \mathrm{l}$ ) in pregnant women found that vitamin $\mathrm{D}$ deficiency varied greatly across Europe, with incidence rates ranging from $18 \%$ to $90 \%$ [2]. At present, there is a lack of data on vitamin D status in large cohorts of healthy pregnant women in 
Northern Ireland; this makes it difficult to develop recommendations for achieving optimal 25-hydroxyvitamin D (25OHD) status in pregnancy.

Pregnancy is associated with altered glucose metabolism, an increase in insulin resistance and a decrease in insulin sensitivity, and changes in lipid metabolism [3]. The regular function of vitamin D is to maintain calcium-phosphate homeostasis [4]; however, there is increasing evidence of a possible beneficial impact of vitamin D sufficiency on glycaemia in pregnancy [5,6]. Gestational diabetes mellitus (GDM) is defined as glucose intolerance with onset or first recognition during pregnancy, as a result of pregnancy-associated insulin resistance and impaired insulin secretion. It occurs in $\sim 2-13 \%$ of all pregnancies, depending on the diagnostic criteria and the population being studied [7,8]. Women with GDM have an increased risk of adverse pregnancy outcomes and subsequent Type 2 diabetes after pregnancy [7]. A recent meta-analyses of observational studies reported that vitamin D deficiency was associated with a significant increased risk of the development of GDM [6,9]; however, a meta-analysis of randomized controlled trials found no difference in the incidence of GDM among women in the control group vs a vitamin D supplement group [10]. The impact of vitamin D deficiency on GDM needs clarification because treatment with 25OHD potentially offers an inexpensive way to reduce the frequency of GDM.

The aim of the present study was to measure $25 \mathrm{OHD}_{2 /} \mathrm{D}_{3}$ and dietary vitamin $\mathrm{D}$ in the cohort of pregnant women in the Belfast Centre of the Hyperglycaemia and Adverse Pregnancy Outcome (HAPO), at 24-32 weeks' gestation, and to investigate the association of 25OHD with markers of glucose, insulin resistance, $\beta$-cell function and lipid levels in these women.

This article is protected by copyright. All rights reserved. 


\section{Participants and methods}

Details of the methodology of the HAPO study have been published elsewhere $[11,12]$. Briefly, the HAPO study was a 15-centre multicultural and multinational study designed to examine the association between maternal hyperglycaemia and adverse pregnancy outcomes in women with singleton pregnancies whose results on an oral glucose tolerance test (OGTT) were below the thresholds for diabetes. All pregnant women at a given centre were eligible to participate. Each participant underwent a standard 75-g OGTT at between 24 and 32 weeks' gestation (optimal: 28 weeks), with sampling of fasting plasma glucose and at $1 \mathrm{~h}$ and $2 \mathrm{~h}$ (glucose assays: Vitros 750; Ortho-Clinical Diagnostics, Raritan, NJ, USA; interassay coefficient of variation 4.4\%). The OGTT results were blinded to the clinician responsible for the care of the pregnant woman unless the fasting plasma glucose level exceeded $5.8 \mathrm{mmol} / \mathrm{l}$ or the 2-h post-load level exceeded $11.1 \mathrm{mmol} / \mathrm{l}$. Additional blood samples were collected concurrently for storage and future biomarker analysis.

Maternal height, weight and blood pressure were measured at the time of the OGTT and data concerning maternal smoking habits and alcohol use were collected using a standardized questionnaire at this visit. In addition, participants completed a semi-quantitative validated food frequency questionnaire (FFQ) at the time of the OGTT, which was used to assess usual dietary intake [13]. Mean dietary vitamin D intake was calculated from the FFQ using the nutritional software package Q-Builder (Questionnaire Design System), version 2.0 (Tinuviel Software, Anglesey, UK), which uses UK food composition tables to quantify nutrient intakes. Quantification of dietary intake of vitamin D was based on food sources alone, as the FFQ was not designed to ascertain the quantification of vitamin D entering the diet via food fortification or vitamin supplementation.

This article is protected by copyright. All rights reserved. 
Levels of $25 \mathrm{OHD}_{2} / \mathrm{D}_{3}$ were measured in serum using a liquid chromatography tandem-mass spectrometry (LC-MS/MS) method (Waters ${ }^{\circledR}$ Xevo TQ-S ${ }^{\circledR}$ and ACQUITY UPLC; Waters, Elstree, UK). The inter-assay coefficients of variation of the method for $25 \mathrm{OHD}_{2}$ and $25 \mathrm{OHD}_{3}$ were $4.4 \%$ and $3.4 \%$ at concentration $16.1 \mathrm{nmol} / \mathrm{l}$, respectively, while the intraassay coefficients of variation were $2.7 \%$ and $2.3 \%$, respectively. The quality and accuracy of serum 25OHD analysis using the LC-MS/MS method in our laboratory was monitored on an ongoing basis through participation in the Vitamin D External Quality Assessment Scheme (Charing Cross Hospital). C-peptide level was measured only in non-haemolysed samples using a two-way immunometric assay on an Autodelfia instrument (Waltham, MA, USA). Lipids were also measured on the Cobas C8000 analyser using the enzymatic colorimetric method. The intra-assay coefficients of variation for all lipids were $<2.5 \%$, and the interassay coefficients of variation for all lipids were $<2.8 \%$. LDL cholesterol level was derived using the Friedewald equation if triglyceride levels did not exceed $4.52 \mathrm{mmol} / \mathrm{l}$. Homeostatic model assessment (HOMA) of insulin resistance and $\beta$-cell function (HOMA-IR and HOMA$\beta$, respectively) were calculated using the HOMA2 calculator [14]. C-peptide was used in the calculation of HOMA-IR and HOMA- $\beta$ as opposed to insulin as it is more stable because of haemolysis. In addition, in a previous publication based on the HAPO study, C-peptide level was used in the HOMA calculations [15].

Overall, 23316 blinded participants successfully completed the HAPO study. Of the 1677 participants at the Belfast centre, 37 were excluded from the study because of OGTT glucose levels exceeding predefined thresholds, leading to unblinding of the caregivers and treatment of the participants $(n=1640,98 \%)$. A further 28 women who were of non-white European ethnicity were also excluded because of the relationship between GDM and ethnicity [16]; this resulted in 1612 women (96\%) in the cohort being available for study. Serological samples for the measurement of vitamin D were available for 1585 women. 
Written informed consent was obtained from all study participants. Ethical approval was obtained from the relevant ethics committee and the research adhered to the tenets of the Declaration of Helsinki.

\section{Statistical analysis}

Statistical analysis was carried out using SPSS version 21 (IBM Corp, Armonk, NY, USA). Variables were examined using normality plots and serum 25OHD level, serum triglyceride level, HOMA-IR and HOMA- $\beta$ were logarithmically transformed to the base 2 as their distributions were positively skewed. The season during which the maternal OGTT was performed was defined as winter/spring (December, January, February, March, April, May) or summer/autumn (June, July, August, September, October, November). Total 25OHD comprised $25 \mathrm{OHD}_{2}$ and $25 \mathrm{OHD}_{3}$, of which $25 \mathrm{OHD}_{3}$ was the main constituent. Vitamin D deficiency in this cohort was defined as $\leq 50 \mathrm{nmol} / \mathrm{l}$ as per Institute of Medicine guidelines [17].

Descriptive statistics are presented for the cohort's continuous demographic and biochemical variables; mean $\pm \mathrm{SD}$ values are given for normally distributed variables and median and interquartile range for non-normally distributed variables, and $n(\%)$ values are used to describe the cohort's categorical variables.

Independent sample $t$-tests and chi-squared tests were used to compare participants who were vitamin D-deficient and -sufficient for continuous and categorical variables, respectively. The results are presented as mean \pm SD for normally distributed variables and geometric mean \pm SD for log-transformed variables. Pearson correlation coefficients were used to assess the association between total 25OHD concentrations and continuous variables.

This article is protected by copyright. All rights reserved. 
Multiple linear regression analysis was used to determine if circulating total 25OHD levels had an independent association with maternal fasting, 1-h and 2-h plasma glucose, HOMAIR, HOMA- $\beta$, total cholesterol, LDL cholesterol, HDL cholesterol and triglycerides, after controlling for confounding variables. Binary logistic regression was performed to determine if maternal total 25OHD level had an independent association with GDM (as defined by the 2013, International Association of the Diabetes and Pregnancy Study Groups/WHO criteria [18].

Variables included in the multiple regression analysis were chosen based on previous literature and prior bivariate results from this cohort. Maternal age at OGTT, maternal height, BMI at OGTT, gestational age at OGTT, smoking during pregnancy and family history of diabetes were identified based on similar literature and analysis [5,19]. In addition, season of sampling and maternal education (years of education) were also included as a result of bivariate analysis. Regression coefficients were back-transformed if the dependent variable was $\log$-transformed. A $P$ value $\leq 0.05$ was considered statistically significant.

\section{Results}

Table 1 shows the clinical and biochemical characteristics of the pregnant women in the Belfast HAPO study. The mean \pm SD age $(n=1585)$ and BMI $(n=1584)$ at the OGTT were $29.7 \pm 5.5$ years and $28.3 \pm 4.6 \mathrm{~kg} / \mathrm{m}^{2}$, respectively. The women underwent blood testing at a mean \pm SD of $29.0 \pm 1.2$ weeks' gestation $(n=1585)$. The prevalence of cigarette smoking and alcohol consumption was relatively high $(24.1 \%$ and $26.9 \%$, respectively). Fasting, 1 -h and 2-h mean \pm SD plasma glucose levels were $4.6 \pm 0.3 \mathrm{mmol} / \mathrm{l}(n=1585), 7.4 \pm 1.6 \mathrm{mmol} / \mathrm{l}$ $(n=1584)$ and $6.0 \pm 1.1 \mathrm{mmol} / \mathrm{l}(n=1585)$, respectively. 
The median (interquartile range) maternal 25OHD concentration was $38.6(24.1-60.7) \mathrm{nmol} / \mathrm{l}$ $(n=1585)$. No 3 -epi-25OHD 2 was detectable in any of the samples. Mean 3-epi-25OHD 3 levels were low $[2.9 \pm 1.9 \mathrm{nmol} / \mathrm{l}(n=1512)]$ and present in $95 \%$ of all participants sampled. Dietary vitamin D from diet alone was low $[3.3 \pm 2.5 \mu \mathrm{g} /$ day $(n=1541)]$; however, it should be noted that the FFQ used in the Belfast HAPO study was not designed to quantify vitamin supplementation or fortified food use. The prevalence of vitamin D deficiency was high, with $65.8 \%$ of women having $25 \mathrm{OHD}$ levels $\leq 50 \mathrm{nmol} / \mathrm{l}$.

Table 2 shows the clinical and biochemical characteristics according to vitamin D deficiency ( $\leq 50 \mathrm{nmol} / \mathrm{l} \mathrm{vs}>50 \mathrm{nmol} / \mathrm{l})$. A significantly higher proportion of smokers during pregnancy were vitamin $\mathrm{D}$-deficient $(P \leq 0.001)$. There was also statistically significant evidence of seasonal variation. A higher proportion of women who were sufficient in vitamin D were sampled in summer and autumn, whereas, a higher percentage of women deficient in vitamin D were sampled in winter and spring $(P \leq 0.001)$. Women who were vitamin D-deficient were more likely to be younger and have a higher BMI than women who were vitamin Dsufficient. Women with vitamin D deficiency had significantly fewer years in education compared with those who were vitamin D-sufficient. No statistically significant differences were observed between women who were vitamin D-deficient or -sufficient in terms of markers of glucose and insulin metabolism. No statistically significant differences in women diagnosed with GDM were observed for those who were vitamin D-deficient and -sufficient (Table 2). In addition, when $25 \mathrm{OHD}$ was expressed as a continuous variable, no statistically significant difference was observed between those diagnosed with and without GDM [36.9 \pm 1.9 and $37.8 \pm 2.0 \mathrm{nmol} / \mathrm{l}$, respectively; $P=0.61$ (data not shown)].

This article is protected by copyright. All rights reserved. 
Circulating levels of 25OHD were not significantly correlated with age, weight or height; however, 25OHD was significantly and positively correlated with length of education $(P \leq 0.001)$. The association between $25 \mathrm{OHD}$ and BMI at OGTT approached significance $[P=0.060$ (data not shown)].

The adjusted analysis involving 25OHD levels and fasting plasma glucose approached significance [regression coefficient $-0.017(95 \% \mathrm{CI}-0.034$ to 0.001$) ; P=0.06$ (Table 3)]. No association was found between 1-h post OGTT glucose and 2-h post OGTT glucose and 25OHD levels. A weak significant positive association was observed between 25OHD and HOMA- $\beta$ [1.013 (95\% CI 1.001 to 1.024$) ; P=0.031]$ in adjusted analysis. A doubling of maternal 25OHD levels was associated with $\sim 1 \%$ higher HOMA- $\beta$. No corresponding association was observed between 25OHD and HOMA-IR. In keeping with these results, no association was observed between vitamin D and GDM.

Weak significant positive associations were observed between vitamin $\mathrm{D}$ and both total cholesterol [0.085 (95\% CI 0.002 to 0.167$) ; P=0.044]$ and HDL cholesterol [0.047 (95\% CI 0.021 to 0.073$) P \leq 0.001$ ] in adjusted analyses.

\section{Discussion}

The results of the present study showed a relatively high prevalence of vitamin D deficiency $(65.8 \%)$ in a white European pregnant population in the northern hemisphere. This may be attributable to a seasonal effect as well as the low intake of dietary vitamin D. We found little association between total 25OHD and traditional markers of GDM during pregnancy. Total 25OHD was associated with HOMA- $\beta$ but no corresponding relationship with HOMA-IR 
was observed. There was a weakly positive association between total $25 \mathrm{OHD}$ and both total cholesterol and HDL.

Vitamin D deficiency is a common disorder globally. A recent systematic review by Saraf et al. [2] found that vitamin D deficiency $(<50 \mathrm{nmol} / \mathrm{l})$ varied around the world. Deficiency was present in $42-72 \%$ of pregnant women in the Americas, $18-90 \%$ in Europe, $46 \%$ in the Eastern Mediterranean, 66-96\% in South-East Asia and 41-97\% in the Western Pacific region [1]. The level of total $25 \mathrm{OHD}$ in the present study was lower than that observed in a similar cohort of pregnant women in the southwest of England [the Avon Longitudinal Study of Parents and Children (ALSPAC) study $(n=3960)$ ], in whom a median (interquartile range) circulating 25OHD level in the third trimester of 67.4 (46.8 to 93.0) nmol/l was reported [20]. In addition, $34 \%$ of participants in that study had $25 \mathrm{OHD}$ levels $<50 \mathrm{nmol} / 1$ in the third trimester [20]. It is conceivable that the higher levels of vitamin D in the ALSPAC study relates to the higher sunshine levels in the southwest of England, which receives 1750 hours of sunshine annually compared with 1450 hours of annual sunshine in Belfast [21]. This suggests there could be significant differences within the UK during pregnancy in terms of endogenous production of vitamin $\mathrm{D}_{3}$. In addition to the reduced production of vitamin $\mathrm{D}_{3}$ in the Belfast HAPO cohort, the dietary intake of vitamin D was low. This might be attributable to the low consumption of fish (oily fish in particular). Participants in the Belfast HAPO cohort on average failed to meet the recommended nutrient intake for vitamin D (10 $\mu \mathrm{g} / \mathrm{day})$ [22]; however, this could be explained by the lack of information on vitamin D derived from vitamin supplementation and fortified foods. Dietary vitamin D consumption was similar to that reported in the latest UK National Diet and Nutrition Survey [23], where the average dietary vitamin D intake was $3.4 \mu \mathrm{g} /$ day. This, coupled with the seasonal effect observed in the present study, suggests that pregnant, white European women in Northern Ireland may 
benefit from enhanced dietary and supplementary strategies to increase 25OHD levels to an optimal level and that existing approaches are insufficient.

In the present study, the weak associations observed between 25OHD and glucose and insulin markers are consistent with the lack of a significant association between 25OHD and GDM. Similar results were reported by Whitelaw et al. [24], who used a similar method of 25OHD analysis to that used in the present study, in their study in 596 white Europeans in England. They observed that $66 \%$ of women were vitamin D-deficient $(\leq 50 \mathrm{nmol} / \mathrm{l})$, and found weak inverse associations between $25 \mathrm{OHD}$ and fasting plasma glucose.

A sub-group of the HAPO cohort at the Brisbane centre $(n=399)$ performed a similar analysis to that of the present study, and on multivariate analysis found that 25OHD was significantly negatively associated with fasting plasma glucose $[-0.047$ (95\% CI -0.084 to -0.010$)$; $P=0.012$ ], but not with 1 -h or 2 -h plasma glucose. In addition, a significant correlation was observed between total 25OHD and HOMA- $\beta(P=0.009)$ in bivariate analysis, but not with HOMA-IR. Participants in the Brisbane HAPO cohort, however, were vitamin D-sufficient (mean \pm SD $25 \mathrm{OHD}$ level $132.5 \pm 44.0 \mathrm{nmol} / \mathrm{l}$ ), whereas, in the present study, the prevalence of vitamin D deficiency was $65.8 \%$ and mean $25 \mathrm{OHD}$ levels were $<50 \mathrm{nmol} / \mathrm{l}$. It was suggested by the authors of the Brisbane study that the association observed in their study would also exist in populations who were vitamin D-deficient [5]. Our results partially confirm their hypothesis as we found a significant association with HOMA- $\beta$, with no corresponding relationship with HOMA-IR in adjusted analysis. In addition, 25OHD had a borderline significant negative association with fasting plasma glucose; however, the associations found in the present study, were mostly weak compared with the Brisbane data. 
The present results are more consistent with those of Josefson et al. [25], who reported findings from a North American subset of the HAPO study $(n=360)$, in which no significant associations were found between $25 \mathrm{OHD}$ and fasting plasma glucose or GDM among participants with a mean $25 \mathrm{OHD}$ concentration of $93 \mathrm{nmol} / \mathrm{l}$. The two studies described above, together with the present study, all used a similar study protocol and laboratory methodology for 25OHD analysis, and they all employed the same diagnostic criteria for GDM, albeit with a spectrum of vitamin D concentrations. The inconsistent results from the three studies support the need for further research, however, and strengthen the case for a large-scale randomized contolled trial in pregnancy to clarify the role of $25 \mathrm{OHD}$ in the development of GDM.

The significant positive associations between 25OHD and total and HDL cholesterol could be a chance finding, although an increase in cholesterol levels during vitamin D deficiency is biologically plausible. For example, Al-Ajlan et al. [26] performed a cross-sectional observational study to examine the effect of vitamin D deficiency on the lipid metabolic profile of women in Saudi Arabia. They observed that serum vitamin D was positively associated with total serum cholesterol and triglyceride levels. The Saudi Arabian study population had a mean total $25 \mathrm{OHD}$ of $19 \mathrm{nmol} / \mathrm{l}$. The authors suggested that the positive association between cholesterol and vitamin $\mathrm{D}$ was attributable to a combination of deficient vitamin D status with the high metabolic demands of pregnancy [26]. Replication of these findings in a general population would be helpful to establish if the association is true, and if there is a level of vitamin D sufficiency (i.e. $>50$ or $>75 \mathrm{nmol} / \mathrm{l}$ ) above which vitamin $\mathrm{D}$ is negatively associated with serum cholesterol. A possible association between vitamin D and cardiovascular disease is well documented in the literature [27-29]. The combination of elevated levels of serum LDL cholesterol and decreased levels of HDL cholesterol increase the risk of atherosclerosis, which leads to cardiovascular disease [30]; therefore, any dietary 
intervention that increases HDL and lowers LDL cholesterol could potentially improve cardiovascular health. It has been suggested that the association between HDL and 25OHD might be attributable to the stimulation of apolipoprotein A1 and/or apolipoprotein A5 by vitamin $\mathrm{D}_{3}[31]$; however, this has yet to be confirmed. In a recent study it was observed that 25OHD was associated with lower HDL levels, and that HDL was associated with lower 25OHD levels, suggesting that the association between 25OHD and HDL is bidirectional [32]. It is possible that the positive association observed between 25OHD and HDL may simply be a marker of overall good health status. In addition, lipid metabolism is different during pregnancy, and the results from the present study may not be reflected in a general population. A number of reviews have been published on vitamin D and lipids in nonpregnant populations $[33,34]$, and most of these found that $25 \mathrm{OHD}$ was positively associated with HDL and negatively associated with LDL cholesterol.

The present study has several limitations. The study population was $100 \%$ white European, and, given the variable rates of vitamin D requirements among different ethnic groups, the results cannot be applied to all population groups. Insulin resistance and $\beta$-cell function were estimated using the HOMA equations. These equations reflect only the fasting state and are less sensitive than direct measurements such as the hyperinsulinaemic-euglycaemic clamp. The BMI used in the HAPO study was measured at 24-32 weeks' gestation and it is possible that BMI at this stage in pregnancy may not be representative of the true BMI status of the mother. In addition, dietary intake was assessed using an FFQ, and not the 'gold standard' method of a food diary.

This article is protected by copyright. All rights reserved. 
Strengths of the present study include the large number of participants studied, the rigorous nature of the research methodology of the HAPO study including the ability to control for an extensive number of confounding variables, the state-of-the-art measurement of maternal vitamin D and its metabolites and the homogeneity of the population.

In conclusion, this study shows that vitamin D deficiency and a low dietary vitamin D intake are common in a large group of pregnant women in Belfast, UK. Weak associations were observed between vitamin D and HOMA- $\beta$, while the association with fasting plasma glucose approached significance. Overall, these results suggest that vitamin D does not have a role in the development of GDM during pregnancy and are consistent with evolving data in the nonpregnant context $[35,36]$. The positive association of 25OHD and HDL merits further investigation to confirm the association and to explore possible biological mechanisms.

\section{Funding sources}

The HAPO study was funded by grants from the National Institute of Child Health and Human Development and the National Institute of Diabetes and Digestive and Kidney Diseases (RO1-HD34242 and RO1- HD34243) and Diabetes UK (RD04/ 0002756), which supported the enrolment and collection of data on participants.

\section{Competing interests}

None declared.

This article is protected by copyright. All rights reserved. 


\section{References}

1. El Koumi MA, Ali YF, Abd El Rahman RN. Impact of maternal vitamin D status during pregnancy on neonatal vitamin D status. Turk J Pediatr 2013;55:371-377.

2. Saraf R, Morton S, Camargo C, Grant C. Global sumary of maternal and newborn vitamin D status- a systematic review. Matern Child Nutr 2016;12:647-668.

3. Walsh J, McGowan CA, Kilbane M, McKenna MJ, McAuliffe FM. The relationship between maternal and fetal vitamin $\mathrm{D}$, insulin resistance, and fetal growth. Reprod Sci 2013;20:536-541.

4. Masuyama R. Role of local vitamin D signaling and cellular calcium transport system in bone homeostasis. J Bone Miner Metab 2014;32:1-9.

5. McLeod D, Warner J, Henman M, Cowley D, Gibbons K, McIntyre H. Associations of serum vitamin D concentrations with obstetric glucose metabolism in a subset of the Hyperglycemia and Adverse Pregnancy Outcome (HAPO) study cohort. Diabet Med 2012;29:e199-204.

6. Zhang M-X, Pan G-T, Guo J-F, Li B-Y, Qin L-Q, Zhang Z-L. Vitamin D Deficiency Increases the Risk of Gestational Diabetes Mellitus: A Meta-Analysis of Observational Studies. Nutrients 2015;7:8366-8375.

7. American Diabetes Association. Gestational diabetes mellitus. Diabetes Care 2004;27:88-90.

8. International Association of Diabetes and Pregnancy Study Groups Consensus Panel. International Association of Diabetes and Pregnancy Study Groups recommendations on the Diagnosis and Classification of Hyperglycemia in Pregnancy. Diabetes Care

This article is protected by copyright. All rights reserved. 
2010;33:676-682.

9. Lu M, Xu Y, Lv L, Zhang M. Association between vitamin D status and the risk of gestational diabetes mellitus: a meta-analysis. Arch Gynecol Obstet 2016;293:959_ 966.

10. Pérez-López FR, Pasupuleti V, Mezones-Holguin E, Benites-Zapata VA, Thota P, Deshpande A et al. Effect of vitamin D supplementation during pregnancy on maternal and neonatal outcomes: a systematic review and meta-analysis of randomized controlled trials. Fertil Steril 2015;103:1278-1288.

11. The Hapo Study Cooperative Research Group. The Hyperglycemia and Adverse Pregnancy Outcome (HAPO) Study. Int J Gynecol Obstet 2002;78:69-77.

12. The Hapo Study Cooperative Research Group. Hyperglycemia and Adverse Pregnancy Outcomes. N Engl J Med 2008;358:1991-2002.

13. Rogers I, Emmett P, Baker D, Golding J, The ALSPAC Study Team. Financial difficulties, smoking habits, composition of the diet and birthweight in a population of pregnant women in the South West of England. Eur J Clin Nutr 1998;52:251-260.

14. Levy J, Matthews D, Hermans M. Correct Homeostasis Model Assessment (HOMA) Evaluation Uses the Computer Program. Diabetes Care 1998;21:2191-2192.

15. Radaelli T, Farrell KA, Huston-Presley L, Amini SB, Kirwan JP, McIntyre HD et al. Estimates of insulin sensitivity using glucose and C-peptide from the hyperglycemia and adverse pregnancy outcome glucose tolerance test. Diabetes Care 2010;33:490494.

This article is protected by copyright. All rights reserved. 
16. Schwartz N, Nachum Z, Green MS. The prevalence of gestational diabetes mellitus recurrence - Effect of ethnicity and parity: A metaanalysis. Am J Obstet Gynecol 2015;213:310-317.

17. Institute of Medicine. Dietary Reference Intakes for Calcium and Vitamin D. Washington, D.C.; 2011.

18. World Health Organization. Diagnostic Criteria and Classification of Hyperglycaemia First Detected in Pregnancy. World Health Organization: Geneva, 2013.

19. Triunfo S, Lanzone A, Lindqvist PG. Low maternal circulating levels of vitamin D as potential determinant in the development of gestational diabetes mellitus. J Endocrinol Invest 2017;40:1049-1059.

20. Lawlor DA, Wills AK, Fraser A, Sayers A, Fraser WD, Tobias JH. Association of maternal vitamin D status during pregnancy with bone-mineral content in offspring: a prospective cohort study. Lancet 2013;381:2176-2183.

21. Met Office. Northern Ireland: climate. 2015.

22. Scientific Advisory Commitee on Nutrition. Vitamin D and Health. London, 2016.

23. Public Health England. National Diet and Nutrition Survey Results from Years 1, 2, 3 and 4 ( combined ) of the Rolling Programme (2008/2009 -2011/2012). Vol. 4. London; 2014.

24. Whitelaw DC, Scally AJ, Tuffnell DJ, Davies TJ, Fraser WD, Bhopal RS et al. Associations of circulating calcium and 25-hydroxyvitamin D with glucose metabolism in pregnancy: a cross-sectional study in European and South Asian women. J Clin Endocrinol Metab 2014;99:938-946.

This article is protected by copyright. All rights reserved. 
25. Josefson JL, Reisetter A, Scholtens DM, Price HE, Metzger BE, Langman CB et al. Maternal BMI Associations with Maternal and Cord Blood Vitamin D Levels in a North American Subset of Hyperglycemia and Adverse Pregnancy Outcome (HAPO) Study Participants. PLoS One 2016;11:e0150221.

26. Al-Ajlan A, Krishnaswamy S, Alokail M, Aljohani N, Al-Serehi A, Sheshah E et al. Vitamin D deficiency and dyslipidemia in early pregnancy. BMC Pregnancy Childbirth 2015;15:314-321.

27. Cashman KD. A review of vitamin D status and CVD. Proc Nutr Soc 2014;73:65-72.

28. Wang L, Song Y, Manson JE, Pilz S, März W, Michaëlsson K et al. Circulating 25hydroxy-vitamin D and risk of cardiovascular disease: a meta-analysis of prospective studies. Circulation 2012;5:819-829.

29. Pilz S, Tomaschitz A, März W, Drechsler C, Ritz E, Zittermann A et al. Vitamin D, cardiovascular disease and mortality. Clin Endocrinol (Oxf) 2011;75:575-584.

30. Bartels A, O’Donoghue K. Cholesterol in pregnancy: a review of knowns and unknowns. Obstet Med 2011;4:147-151.

31. Shirts B, Howard M, Hasstedt S, Nanjee M, Knight S, Carlquist JF et al. Vitamin D dependent effects of APOA5 polymorphisms on HDL cholesterol. Atherosclerosis 2012;222:167-174.

32. Vitezova A, Voortman T, Zillikens MC, Jansen PW, Hofman A, Uitterlinden AG et al. Bidirectional associations between circulating Vitamin D and cholesterol levels: The Rotterdam Study. Maturitas 2015;82:411-417.

33. Jorde R, Grimnes G. Vitamin D and metabolic health with special reference to the 
effect of vitamin D on serum lipids. Prog Lipid Res 2011;50:303-312.

34. Zittermann A, Gummert JF, Börgermann J. The role of vitamin D in dyslipidemia and cardiovascular disease. Curr Pharm Des 2011;17:933-942.

35. Wallace IR, McKinley MC, McEvoy CT, Hamill LL, Ennis CN, McGinty A et al. Serum 25-hydroxyvitamin D and insulin resistance in people at high risk of cardiovascular disease: a euglycaemic hyperinsulinaemic clamp study. Clin Endocrinol (Oxf) 2016;85:386-392.

36. Wallace H, Holmes L, Ennis C, Cardwell C, Woodside J, Young I et al. The effect of vitamin D supplementation on insulin resistance in a pre-diabetic population:a doubleblind randomised placebo controlled trial. Ir J Med Sci 2016;185:S374.

This article is protected by copyright. All rights reserved. 
Table 1 Clinical and biochemical characteristics of pregnant women in the Belfast centre of the HAPO study at an average of 28 weeks' gestation

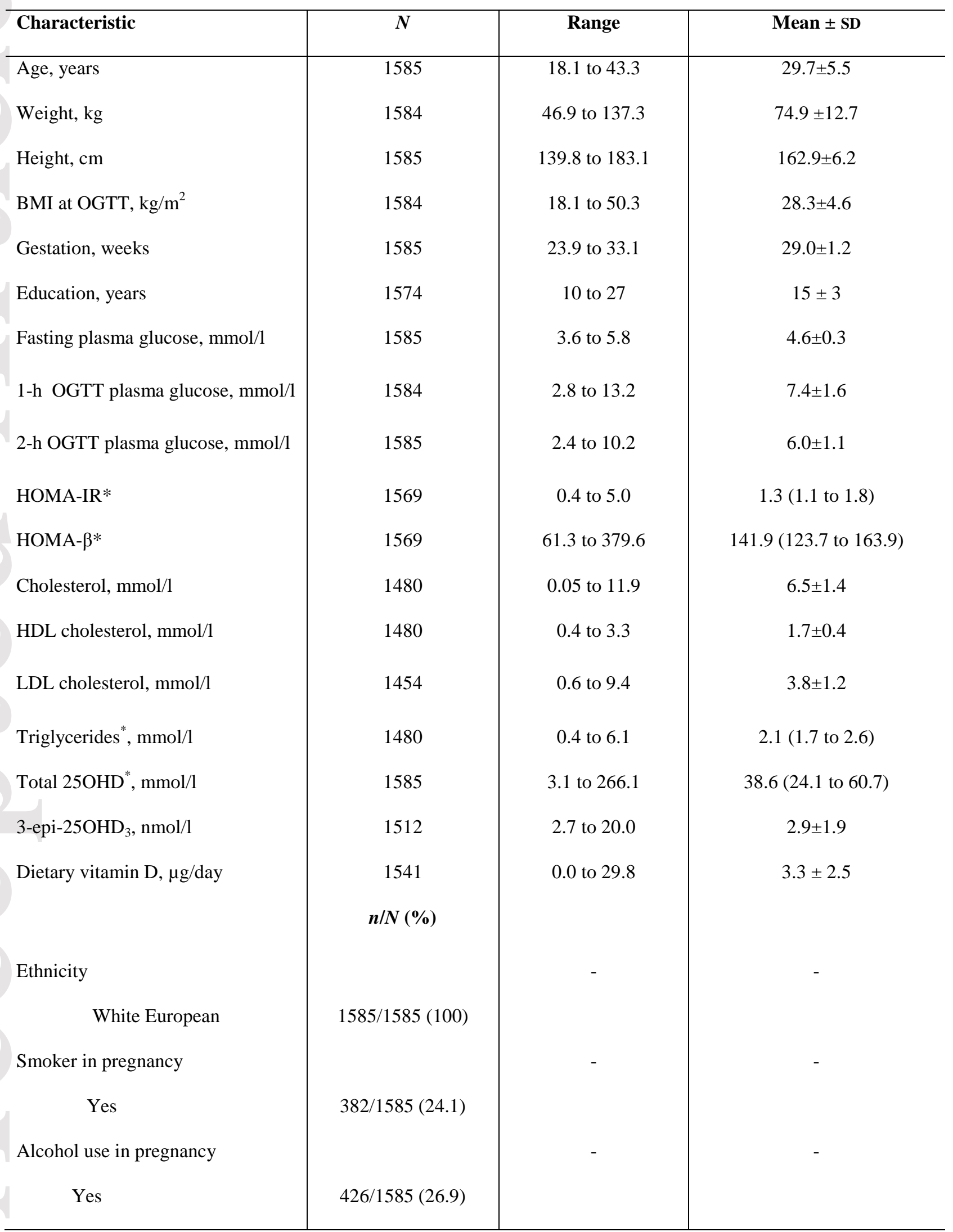

This article is protected by copyright. All rights reserved. 
Season of sampling

Summer and Autumn

Winter and Spring

Family history of diabetes

Yes

Diagnosis of GDM

$$
\text { Yes }
$$

Vitamin D deficiency $(\leq 50 \mathrm{nmol} / \mathrm{l})$
$813 / 1585(51.3)$

$772 / 1585(48.7)$

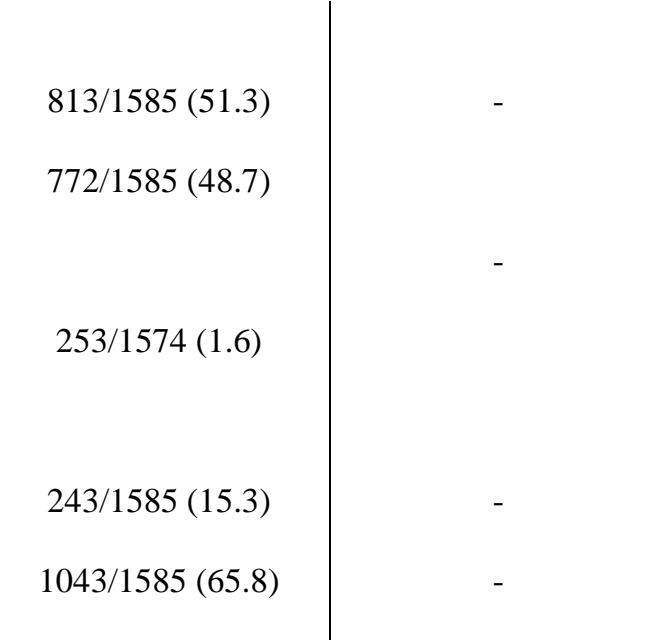

$1043 / 1585(65.8)$

25OHD, 25-hydroxyvitamin D; GDM, gestational diabetes mellitus; HOMA-IR, homeostatic model assessment of insulin resistance; HOMA- $\beta$, homeostatic model assessment of $\beta$-cell function. "Reported as median and interquartile range.

GDM defined retrospectively according to International Association of the Diabetes and Pregnancy Study Groups/WHO criteria.

This article is protected by copyright. All rights reserved. 
Table 2 Comparison of clinical and biochemical characteristics of pregnant women in the Belfast centre of the HAPO study at an average of 28 weeks' gestation according to maternal vitamin D-deficient and -sufficient serum concentrations

\begin{tabular}{|c|c|c|c|}
\hline Variable & Serum vitamin $\mathrm{D} \leq \mathbf{5 0} \mathrm{nmol} / \mathrm{l}$ & $\begin{array}{c}\text { Serum vitamin D }>\mathbf{5 0} \\
\mathrm{nmol} / \mathrm{l}\end{array}$ & $P$ \\
\hline Age, years & $29.4 \pm 5.6$ & $30.1 \pm 5.2$ & 0.03 \\
\hline Weight, kg & $75.4 \pm 13.3$ & $74.1 \pm 11.5$ & 0.05 \\
\hline Height, $\mathrm{cm}$ & $162.8 \pm 6.4$ & $163.1 \pm 6.0$ & 0.42 \\
\hline $\mathrm{BMI}$ at $\mathrm{OGTT}, \mathrm{kg} / \mathrm{m}^{2}$ & $28.5 \pm 4.8$ & $27.9 \pm 4.0$ & 0.01 \\
\hline Gestation, weeks & $29.1 \pm 1.3$ & $29.0 \pm 1.2$ & 0.23 \\
\hline Smoker in pregnancy, $n(\%)$ & & & \\
\hline Yes & $296(28.4 \%)$ & $86(15.9 \%)$ & $\leq \mathbf{0 . 0 0 1}$ \\
\hline No & $747(71.6 \%)$ & $456(84.1 \%)$ & \\
\hline Alcohol use in pregnancy, $n(\%)$ & & & \\
\hline Yes & $268(25.7 \%)$ & $426(29.2 \%)$ & 0.14 \\
\hline No & $775(74.3 \%)$ & $1159(70.8 \%)$ & \\
\hline Education, years & $14.7 \pm 2.8$ & $15.3 \pm 2.9$ & $\leq \mathbf{0 . 0 0 1}$ \\
\hline Season of sampling, $n(\%)$ & & & \\
\hline Summer and Autumn & $416(39.9 \%)$ & $397(73.2 \%)$ & $\leq 0.001$ \\
\hline Winter and Spring & $627(60.1 \%)$ & $145(26.8 \%)$ & \\
\hline $\begin{array}{l}\text { Family history of diabetes, } n(\%) \\
\qquad \begin{array}{c}\text { Yes } \\
\text { No }\end{array}\end{array}$ & $\begin{array}{l}167(16.2 \%) \\
865(83.8 \%)\end{array}$ & $\begin{array}{l}86(15.9 \%) \\
456(84.1 \%)\end{array}$ & 0.87 \\
\hline Fasting plasma glucose, $\mathrm{mmol} / \mathrm{l}$ & $4.6 \pm 0.3$ & $4.6 \pm 0.3$ & 0.07 \\
\hline $\begin{array}{l}\text { 1-h OGTT plasma glucose, } \\
\mathrm{mmol} / \mathrm{l}\end{array}$ & $7.4 \pm 1.6$ & $7.4 \pm 1.6$ & 0.45 \\
\hline 2-h OGTT plasma glucose, & $6.0 \pm 1.1$ & $6.0 \pm 1.2$ & 0.56 \\
\hline
\end{tabular}

This article is protected by copyright. All rights reserved. 
$\mathrm{mmol} / 1$

HOMA-IR

$1.4 \pm 1.4$

$1.4 \pm 1.4$

0.22

HOMA- $\beta$

$142.3 \pm 1.3$

$141.9 \pm 1.3$

0.84

Diagnosis of GDM, $n(\%)$

$$
\begin{aligned}
& \text { Yes } \\
& \text { No }
\end{aligned}
$$

$69(16.2 \%)$

$4(13.7 \%)$

0.18

$874(83.8 \%)$

$468(86.3 \%)$

Cholesterol, mmol/l

$6.4 \pm 1.4$

$6.6 \pm 1.4$

0.08

HDL cholesterol, mmol/l

$1.6 \pm 0.4$

$1.7 \pm 0.4$

$\leq 0.001$

LDL cholesterol, mmol/1

$3.8 \pm 1.2$

$3.9 \pm 1.2$

0.32

$2.1 \pm 1.4$

$2.0 \pm 1.4$

0.71

$28.7 \pm 11.5$

$80.1 \pm 26.2$

$\leq \mathbf{0 . 0 0 1}$

$2.0 \pm 1.1$

$4.5 \pm 2.2$

$\leq 0.001$

$3.2 \pm 2.3$

$3.5 \pm 2.8$

0.01

25OHD, 25-hydroxyvitamin D; GDM, gestational diabetes mellitus; HOMA-IR, homeostatic model assessment of insulin resistance; HOMA- $\beta$, homeostatic model assessment of $\beta$-cell function; OGTT, oral glucose tolerance test.

Values are expressed as mean \pm SD unless otherwise indicated.

GDM defined retrospectively according to International Association of the Diabetes and Pregnancy Study Groups/WHO criteria.

This article is protected by copyright. All rights reserved. 
Table 3 Unadjusted and adjusted associations of maternal 25-hydroxyvitamin D at an average of 28 weeks' gestation with maternal glucose, $\beta$ cell function, insulin resistance and lipid markers

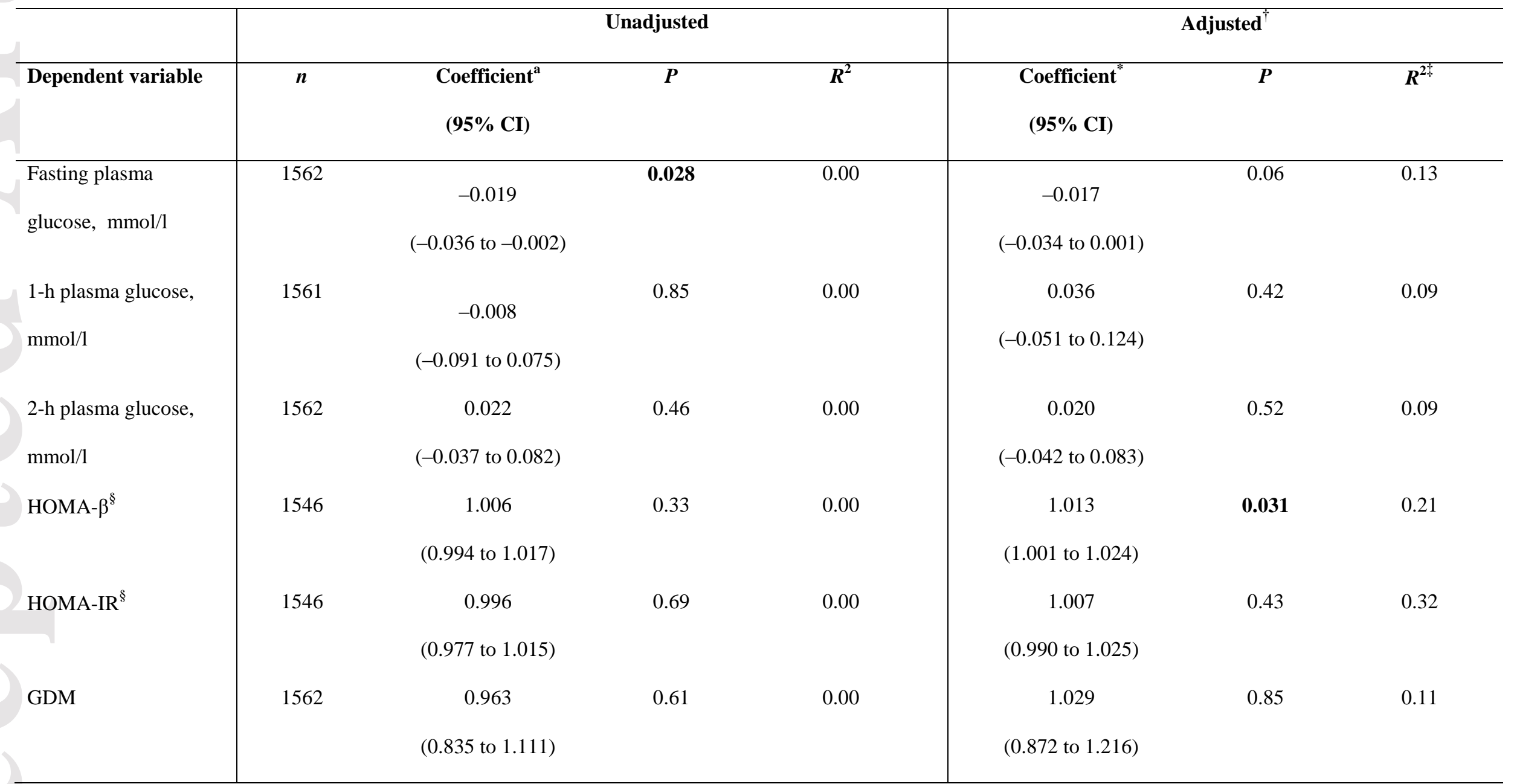

This article is protected by copyright. All rights reserved. 


\begin{tabular}{|c|c|c|c|c|c|c|c|}
\hline $\begin{array}{l}\text { Triglycerides }^{\S}, \\
\mathrm{mmol} / \mathrm{l}\end{array}$ & 1457 & $\begin{array}{c}0.992 \\
(0.973 \text { to } 1.011)\end{array}$ & 0.40 & 0.00 & $\begin{array}{c}1.015 \\
(0.994 \text { to } 1.035)\end{array}$ & 0.17 & 0.09 \\
\hline Cholesterol, mmol/l & 1457 & $\begin{array}{c}0.062 \\
(-0.014 \text { to } 0.139)\end{array}$ & 0.11 & 0.00 & $\begin{array}{c}0.085 \\
(0.002 \text { to } 0.167)\end{array}$ & 0.044 & 0.04 \\
\hline $\begin{array}{l}\text { LDL cholesterol, } \\
\mathrm{mmol} / \mathrm{l}\end{array}$ & 1431 & $\begin{array}{c}0.012 \\
(-0.053 \text { to } 0.077)\end{array}$ & 0.72 & 0.00 & $\begin{array}{c}0.023 \\
(-0.047 \text { to } 0.093)\end{array}$ & 0.52 & 0.04 \\
\hline $\begin{array}{l}\text { HDL cholesterol, } \\
\mathrm{mmol} / \mathrm{l}\end{array}$ & 1457 & $\begin{array}{c}0.053 \\
(0.029 \text { to } 0.077)\end{array}$ & $<0.001$ & 0.01 & $\begin{array}{c}0.047 \\
(0.021 \text { to } 0.073)\end{array}$ & $<0.001$ & 0.06 \\
\hline
\end{tabular}

25OHD, 25-hydroxyvitamin D; GDM, gestational diabetes mellitus; HOMA-IR, homeostatic model assessment of insulin resistance; HOMA- $\beta$, homeostatic model assessment of $\beta$-cell

function; OGTT, oral glucose tolerance test.

* Regression coefficients represent the additive effect on the dependent variable associated with a doubling in maternal serum 25OHD level.

${ }^{\dagger}$ Adjusted for season of sampling, maternal BMI at OGTT, maternal age, smoker during pregnancy, maternal education, maternal height, gestational age at OGTT and family history of diabetes as analysed by multiple linear regression.

${ }^{t} R^{2}$ value represents the entire adjusted model.

${ }^{\S}$ Regression coefficient back transformed $\left(2^{\wedge}\right.$ (regression coefficient) as a result of the dependent variable being log-transformed.

GDM defined retrospectively according to International Association of the Diabetes and Pregnancy Study Groups/WHO criteria.

This article is protected by copyright. All rights reserved. 